\title{
COMMENTARY Personality disorder and mental health legislation in the $\mathrm{UK}^{\dagger}$ COMMENTARY ON... PERSONALITY DISORDER AND THE MENTAL HEALTH ACT 1983 (AMENDED)
}

\author{
Lindsay D. G. Thomson
}

\section{Lindsay D. G. Thomson is a reader in forensic psychiatry at the University of Edinburgh, and Medical Director of The State Hospitals Board for Scotland and the Forensic Mental Health Services Managed Care Network. Her research interests include the impact of legislative change, interventions and outcomes in mentally disordered offenders, and risk of harm to others. Correspondence Dr Lindsay D. G. Thomson, Department of Psychiatry, University of Edinburgh, Kennedy Tower, Morningside Park, Edinburgh EH10 5HF, UK. Email: I.d.g.thomson@ed.ac.uk}

'See pp. 329-335, this issue.

‡For a discussion in Advances of treatment within the DSPD programme and of the concept of DSPD see: Howells K, Krishnan G, Daffern M (2007) Challenges in the treatment of dangerous and severe personality disorder. 13: 325-32; Kingdon D (2007) DSPD or 'Don't Stigmatise People in Distress'. 13: 333-5. Ed.

\section{SUMMARY}

This commentary explores the issue of personality disorder and mental health legislation from a UK perspective, highlighting the differences between its four countries and three mental health acts. It discusses data from Scotland that support the contention that the addition of the term 'personality disorder' to mental health legislation is not alone sufficient to change current practice. The legislative criterion of risk to others is discussed and the varying responses in the UK to the contentious issue of preventive detention, highly likely to be relevant to serious offenders with personality disorder, are described, including the indeterminate sentence of imprisonment for public protection and the order of lifelong restriction. It is concluded that, regardless of location, care of patients with a primary diagnosis of personality disorder will be driven forward not by legislation but by service development, research and changing attitudes.

\section{DECLARATION OF INTEREST}

None.

The assessment and management of people with personality disorder is an integral part of psychiatric practice. No longer can personality disorder be a label that leads to rejection by UK psychiatric services (National Institute for Mental Health in England 2003; Centre for Change and Innovation 2005). Sen $\&$ Irons (2010, this issue) pose an interesting question as to whether the new mental health legislation for England and Wales will influence practice and use of detention. Such legislation cannot, however, be considered in isolation, as there has been considerable development of services and supporting mechanisms for the assessment and treatment of people with personality disorder in recent years in England and Wales. These include:

- investment by the Department of Health and the Home Office in establishing pilot services for people with personality disorder;
- the development of the controversial concept of dangerous and severe personality disorder (DSPD) $)^{\ddagger}$ and the creation of four DSPD units for men (two in prison and two in high-security hospitals, although it is now planned to close the latter) with a total of 300 beds (Department of Health 2008);

- the creation of the multi-agency public protection arrangements (MAPPA), which require police, probation and prison officers, in conjunction with health and social services, to work together to manage the risk posed by dangerous offenders in the community.

Northern Ireland and Scotland have not seen the development of similar services for people with personality disorder, although Scotland has new mental health legislation that specifically includes personality disorder and has introduced MAPPA, whereas Northern Ireland has in place a multi-agency sex offender risk assessment and managementstrategy (MASRAM). Thus, devolution provides a natural experimental environment in which to examine the effects of service and legislative change. Interestingly, the Northern Irish Review of Mental Health and Learning Disability, in its report on forensic services (Bamford Review of Mental Health and Learning Disability 2006), suggests that specific units should be developed for offenders with personality disorder despite the current legislative position, which does not permit the detention of those with a primary diagnosis of personality disorder (Thomson 2008). The Scottish Government established a personality disorder network (www.scottishpersonalitydisorder.org) but no money has been targeted at specific services.

\section{Definition of mental disorder}

Sen $\mathcal{E}$ Irons rightly highlight that the original Mental Health Act 1983 for England and Wales did not mention personality disorder but used the term psychopathic disorder meaning 'a persistent disorder or disability of mind (whether or not 
including significant impairment of intelligence) which results in abnormally aggressive or seriously irresponsible conduct on the part of the person concerned'. A similar position was found in the Mental Health (Scotland) Act 1984, which, although not using the term psychopathic disorder, employed exactly the same definition. In Scotland, personality disorder was specified under the definition of mental disorder in 1999 as an amendment to the Mental Health (Scotland) Act 1984 and is contained within the Mental Health (Care and Treatment) (Scotland) Act 2003.

Sen $\&$ Irons recognise that abolishing the requirement for abnormally aggressive or seriously irresponsible conduct could result in the detention of more patients with personality disorder, but they argue that this will not happen because of the need to provide evidence to fulfil the criteria for detention, in particular that the mental disorder is of a nature or degree that makes it appropriate for them to receive medical treatment in hospital. Unfortunately, in Scotland, the Mental Welfare Commission has no detail on the number of times personality disorder was the primary diagnosis under the 1984 Act. There was, however, no discernible change in the use of short-term orders (28 days) following the introduction of personality disorder into the 1999 Act (1575 short-term orders were issued in 1997-1998, and 1579 in 2000-2001), but this was not widely publicised outwith forensic psychiatry. A primary diagnosis of personality disorder was applicable to only 3\% of patients detained under the new short-term detention certificate in 2008-2009, and the absolute number fell from 133 cases in 2007-2008 to 111 in 2008-2009 (Mental Welfare Commission for Scotland 2009). However, the first full year of figures available for the new Act (2006-2007) showed only 42 cases, suggesting that the new legislation may be having a limited effect even in the absence of the development of specific services.

It should be recognised that the criteria for detention are different in Scotland, particularly the criterion on whether the patient has significantly impaired ability to make decisions about their treatment. It would appear, however, from experience in Scotland that there is evidence to support Sen $\&$ Irons' contention that the addition of the term personality disorder to mental health legislation is not alone sufficient to change current practice.

\section{Risk to others}

Sen $\&$ Irons set out a coherent argument that links necessity, appropriateness and treatment availability to explain why, in their view, the treatability test essentially remains in place, but they do not address the risk test. It is in the nature of the various subtypes of personality disorder that the issue of distress to self or to others is decided. For example, the dissocial, paranoid and schizoid subtypes are more likely to lead to harm to others whereas the borderline, histrionic and dependent primarily cause distress to the individual.

One of the most contentious issues in England and Wales during the debate on new mental health legislation was preventive detention. This was taken into the Criminal Justice Act 2003, which introduced new indeterminate sentences for 'dangerous offenders', whose eligibility for release is dependent on the level of risk they pose in terms of sexual and/or violent reoffending. Offenders with personality disorders are highly likely to be prevalent in this group. Under Section 225 of the Criminal Justice Act 2003, the courts will impose an indeterminate sentence of 'imprisonment for public protection' on offenders who: are aged 18 or over; are convicted of a serious specified violent or sexual offence for which the maximum penalty is 10 years or more; and, in the court's opinion, pose a significant risk of harm to the public.

In Scotland, the MacLean Committee took a different approach to dealing with 'serious violent and sexual offenders', including those with personality disorders (Scottish Executive 2000). It concluded that offenders with personality disorders who are assessed as high risk should be managed along the lines recommended for other high-risk offenders, with the emphasis on the offence and risk. The Committee's recommendations were enacted in the Criminal Justice (Scotland) Act 2003. In 2004, the Risk Management Authority (RMA) was established.

The Act introduced the 'risk assessment order' and 'order for lifelong restriction'. Risk assessment orders provide a 90 (maximum 180) day period of assessment to allow the preparation of a risk assessment report to assist the court in determining whether the Act's 'risk criteria' (Box 1) are met. A

\section{B0X 1 The risk criteria}

'For the purposes of sections 195(1), 210B(2), 210D(1) and $210 F(1)$ and (3) of this Act, the risk criteria are that the nature of, or the circumstances of the commission of, the offence of which the convicted person has been found guilty either in themselves or as part of a pattern of behaviour are such as to demonstrate that there is a likelihood that he, if at liberty, will seriously endanger the lives, or physical or psychological well-being, of members of the public at large.'

Criminal Justice (Scotland) Act 2003: Part 1, Section $210 \mathrm{E}$ 
risk assessment order can be applied by the courts to an offender convicted of a serious violent or sexual offence, or an offence that endangers life. The emphasis is on a clinical risk assessment. An order for lifelong restriction is a lifelong sentence imposed if the court believes that, on a balance of probabilities, the risk criteria are met. Between their introduction in 2006 and February 2010, 46 orders for lifelong restriction had been applied in Scotland (MacAskill 2010). This is markedly different from the situation in England and Wales, where the indeterminate sentence of imprisonment for public protection can be applied without any formal assessment of risk: to date, over 5000 of these sentences have been imposed (Prison Reform Trust 2010).

\section{Community treatment orders}

Sen $\&$ Irons argue somewhat optimistically that the introduction of community treatment orders (CTOs) in England and Wales may result in patients with a personality disorder reaching the community earlier and will ensure that community services are available. They do acknowledge the need for patient cooperation to engage in therapy and the problem of what to do, other than recall for 72 hours, if the patient breaches their conditions. The introduction of compulsory treatment orders (CompTOs) in Scotland, which can be applied without initial detention in hospital, has not resulted in an increase in the number of longterm orders (6 months) (1054 Section 18 orders were imposed in 1998-1999, and 1023 CompTOs in 2008-2009) but the detention of very small numbers of patients with a primary diagnosis of personality disorder (Earle 2020; Mental Welfare Commission 2010). In 2008-2009, only 7 patients with a primary diagnosis of personality disorder were newly detained under CompTOs.
Overall, Sen $\&$ Irons are arguing that the 2007 amendments to the Mental Health Act 1983 will not make much difference to patients in England and Wales with a primary diagnosis of personality disorder. I suspect they are right. It is service development, research and changing attitudes, rather than legislation, that will drive this forward.

\section{References}

Bamford Review of Mental Health and Learning Disability (Northern Ireland) (2006) Forensic Services. RMHLDNI (http://www.rmhldni.gov. uk/forensic_services_report.pdf).

Centre for Change and Innovation (2005) Personality Disorder in Scotland: Demanding Patients or Deserving People? Scottish Executive.

Department of Health, Home Office, HM Prison Service (2008) Dangerous and Severe Personality Disorder (DSPD) High Secure Services For Men: Planning and Delivery Guide. Home Office.

Earle M (2002) The Mental Health (Scotland) Bill 2: Compulsory Treatment. The Scottish Parliament (http://www.scottish.parliament.uk/ business/research/pdf_res_brief/sb02-106.pdf).

MacAskill K (2010) Written answer to S3W-31340: Justice. In Parliamentary Questions \& Answers, Monday 22 February 2010. The Scottish Parliament (http://www.scottish.parliament.uk/business/pqa/ wa-10/wa0222.htm).

Mental Welfare Commission for Scotland (2009) Annual Report 200809: Key Messages and Challenges. Mental Welfare Commission for Scotland.

Mental Welfare Commission for Scotland (2010) Annual Monitoring Report: Overview 2008-2009. Mental Welfare Commission for Scotland (http://reports.mwcscot.org.uk/annual_monitoring/overview2008-2009/ newordersgrantedin2008-09/compulsory_treatment_orders_09.aspx).

National Institute for Mental Health in England (2003) Personality Disorder: No Longer a Diagnosis of Exclusion. Policy Implementation Guidance of the Development of Services for People with Personality Disorder. NIMHE.

Prison Reform Trust (2010) Inspectorates criticise "unsustainable" indeterminate sentences \& call for ministerial review. Prison Reform Trust (http://www.prisonreformtrust.org.uk/standard.asp?id=2103).

Scottish Executive (2000) Report of the Committee on Serious Violent and Sexual Offenders. Scottish Executive.

Thomson LDG (2008) The forensic mental health system in the United Kingdom. In Handbook of Forensic Mental Health (eds K Soothill, P Rogers, M Dolan): pp 19-63. Willan Publishing. 